\title{
In vitro development of sugarcane seedlings using ethephon or gibberellin
}

\author{
Luciane de Siqueira Mendes ${ }^{*}$, Marcia Eugenia Amaral Carvalho', \\ Willian Rodrigues Macedo'2, Paulo Roberto de Camargo e Castro'
}

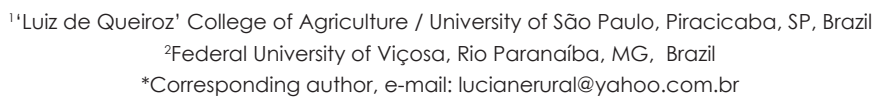

\begin{abstract}
The use of plant growth regulators is directly related to the success of in vitro propagation, which is an advantageous alternative to obtain seedlings on a commercial scale. This study aimed to evaluate the in vitro development of 'IAC 95-5000' sugarcane seedlings after the addition of different doses of ethephon $\left(0,25,50,100\right.$ and $\left.200 \mathrm{mg} \mathrm{L}^{-1}\right)$ or gibberellic acid $(0,2.5,5.0,7.5$ and $10.0 \mathrm{mg} \mathrm{L}^{-1}$ ) to the culture medium. Ethephon increased the number of tillers (up to $231.70 \%$ ), reduced height of the main tiller ( 44.66 to $60.47 \%$ ), and did not affect the shoot's fresh and dry mass. On the other hand, gibberellin decreased the number of tillers and negatively changed biomass partitioning. It is concluded that the use of ethephon is a potential strategy to enhance in vitro production of 'IAC 95-5000' sugarcane seedlings, since it increased the number of usable shoots in subsequent subcultures, and its effects on height reduction can be reversible. However, the use of the tested doses of gibberellic acid is not recommended, because it impaired seedling development of this sugarcane variety.
\end{abstract}

Keywords: ethylene, gibberellic acid, tissue culture, Saccharum spp

Sugarcane is the most efficient bioenergetic crop in tropical and subtropical regions, being also the major source $(80 \%)$ of sugar in the world (Waclawovsky et al., 2010; Smiullah et al., 2013). Furthermore, it is used for animal feeding, production of acetic acid, butanol and biopolymers, as well as a potential source of cellulose for textile fiber (Garcia et al., 2007; Costa et al., 2013). Due to its wide use and economic relevance, high investments are been applied in sugarcane breeding and seedling production; for this purpose, several biotechnological tools were employed (Snyman et al., 2011; Smiullah et al., 2013; Ramiro et al.,
2016). The in vitro tissue culture stands out among these tools, since it allows large-scale production of uniform and disease-free sugarcane seedlings (Begum et al., 2011; Snyman et al., 2011; Smiullah et al., 2013).

The success of in vitro culture depends on multiple factors, such as plant varieties, type of tissue explant, culture conditions, type and composition of medium, and use of plant growth regulators (Garcia et al., 2007; Begum et al., 2011; Snyman et al., 2011; Smiullah et al., 2013; Maluta et al., 2013; Hajari et al., 2015). There are several studies about the influence of plant growth regulators on 'in vitro' culture; however, 
ethylene and gibberellin effects on sugarcane development are scarce. Ethylene is a gaseous plant hormone that has been related to the fruit ripening, senescence, flowering, and in several processes involving in the perception and signaling of external stimulus (Tsuchisaka et al., 2009; Davies, 2010; Taiz \& Zeiger, 2013). Under in vitro conditions, ethylene enhanced the regeneration efficiency, increased the shoots number and height, improved rooting and stimulated the tracheary element differentiation (Prameswara et al., 2009; Pesquet \& Tuominem, 2011; Yasmin et al., 2014).

Regarding gibberellins, this plant hormone influences germination, seedling growth, stem elongation, leaf development, bud outgrowth, flower induction, and xylem expansion (Gabriele et al., 2010; Ikezaki et al., 2010; Mauriat et al., 2011; Nadeau et al., 2011; Zhao et al., 2011; Taiz \& Zeiger, 2013). Application of gibberellin to the culture media inhibited adventitious root formation (Niu et al., 2013), but promoted shoot development and multiplication in Lotus corniculatus (Nikolic et al., 2010) and Selaginella microphylla (Jha et al., 2013). This study aimed to evaluate the effects of different doses of ethephon or gibberellic acid on in vitro development of sugarcane seedlings.

In vitro pre-established seedlings of sugarcane (Saccharum spp. variety IAC 95-5000) were selected and propagated into vials (350 $\mathrm{mL}$ ) with $50 \mathrm{~mL}$ of solid MS medium (Murashige \& Skoog, 1962) containing $30 \mathrm{~g} \mathrm{~L}^{-1}$ of sucrose. For seedling development, the flasks were kept for 20 days in a growth chamber at $25 \pm 2^{\circ} \mathrm{C}$ and 16-hour light ( $30 \mathrm{mM} \mathrm{cm}^{-2}$ ), 8-hour dark lighting photoperiod.

Seedlings with $4 \mathrm{~cm}$-height and a single stem were selected from the ones that were cultivated in the flasks mentioned above. Then, seedlings were put for the second time in MS medium (Murashige \& Skoog, 1962). At this stage, plant growth regulators were added to the medium. Ethephon (2-chloroethylphosphonic acid) at concentrations of 0, 25, 50, 100 and $200 \mathrm{mg} \mathrm{L}^{-1}$ and gibberellic acid $\left(\mathrm{GA}_{3}\right)$ at concentrations of $0,2.5,5.0,7.5$ and $10.0 \mathrm{mg} \mathrm{L}^{-1}$ were used. For comparison, the same control (without addition of plant growth regulators) was used as reference for both experiments (ethephon and gibberellin). After this step, the flasks were put back in the growth chamber.

On the $30^{\text {th }}$ day after the addition of plant growth regulators to the culture medium, seedlings were collected to analyze the following parameters: number of tillers; height of the main tiller [measured from the shoot collar to the tip of the highest leaf $(\mathrm{cm})$ ]; shoot fresh and dry mass [stem and leaves (mg)]; and roots fresh and dry mass (mg). Furthermore, root: shoot ratio (both for the fresh and dry masses) was also calculated.

The experiment was arranged in a completely randomized design, with 5 treatments and 5 replicates, totaling 25 plots with five seedlings each. Obtained data were submitted to analysis of variance and regression (both at 5\% error probability) using the SAS statistic software (SAS Institute, 2011). Significant regression equations (linear, quadratic or cubic) were used to express the variable behavior as a function of increased doses. To fit the statistical assumptions of the variance analysis, data of root: shoot fresh mass ratio (gibberellic acid trial), shoots dry mass (gibberellic acid trial) and height (ethephon trial) were transformed to $\log _{10} x, x^{-1.1}, 1 / x$ (respectively), as recommended by tool "Guided Data Analysis" of the SAS program (SAS Institute, 2011).

As observed in Figure 1, the addition of ethephon to the culture medium significantly increased the number of tillers in sugarcane seedlings (up to 231.70\%). According Davies (1995), ethephon is a compound absorbed by plants and converted into ethylene inside cells, leading to the autocatalytic production of endogenous ethylene. The increased ethylene content in plant tissues can promote tillering by inhibiting basipetal transport of auxin; however, it can also decrease cell division (Davies, 1995), which can explain the reduction in main tiller height in seedlings (from 44.66 to $60.47 \%$, Figure 1) (. Interestingly, this hormone can generate the same effect by decreasing the endogenous synthesis of gibberellin, which is a hormone responsible for cell elongation and division (Pearce et al., 1996).

The positive role of ethylene on sugarcane tillering was also reported by Mishra et al. (2014) by using contrasting approaches. These 
authors applied both ethylene inhibitors (AVG, $A O A$ and $\left(\mathrm{COCl}_{2}\right.$ ) and precursor (ethephon) in the culture media, being observed reductions and increments, respectively, in the number of tiller production. It seems that ethylene plays a key role in the success of in vitro culture of several species by improving shoot development. Application of ethylene in the culture media stimulated the tillering in rice (Yasmin et al., 2014) and Ptilotus spp. (Prameswara et al., 2009). On the other hand, there were reductions in the percentage of tomato plants with buds, when explants were grown under sub-optimum ethylene concentrations (Trujillo-Moya \& Gisbert, 2012).

Ethephon exerted no effects on the total biomass of sugarcane shoots, even after the high increase in the number of tillers, probably due to the concurrent decrease in the height and increase in the thickness of the main tiller (Figure 2). The increased main tiller thickness may be triggered by increasing parenchymatous cell volume (Martins \& Castro, 1999) and enhancing tracheary element differentiation (Pesquet \& Tuominen, 2011) due to ethylene overproduction in explant tissues. Upon ethephon application, there were decreases in the root dry mass and changes in the root-shoot partitioning (Figure 1). Although ethylene can improve root formation (Prameswara et al., 2009) and development (Trujillo-Moya \& Gisbert, 2012), its effects are dose and species-dependent. Upon explant exposure to $25 \mathrm{mg} \mathrm{L}-1$ ethephon, there was little effect on the root dry mass, but a high increase in the number of tillers (Figure 1). However, the use of higher doses of ethephon than the one mentioned above caused negative effects on the root dry mass.

The use of gibberellin also triggered reductions in the root fresh mass of treated seedlings when compared to control (Figure 3), probably by inhibiting the initiation of lateral root primordia (Gou et al., 2010) and/ or by unbalancing the synthesis or transport of endogenous hormones (Nikolic et al., 2010). In rice seedlings, there were reductions in the adventitious root growth after application of gibberellin in the media (Lo et al., 2008).

Gibberellin-treated explants exhibited a more elongated (up to $34.70 \%$ ) and thinner main tiller than the control explants (Figure 4). According to Davies (1995), gibberellin usually stimulates bud development due to increases in cell division and elongation, providing increments in internode length and, consequently, in plant height.

The stimulatory effect of gibberellin on plant height was also observed in pea explants treated with an anti-gibberellin compound (Ribalta et al., 2014). The internode length was increased by the decreasing concentration of this compound, which did not affected the number of nodes. However, gibberellin diminished the diameter of the main tiller, which also presented an abnormal growth ( Figure 4). These results may be triggered by decreases in the radial volume

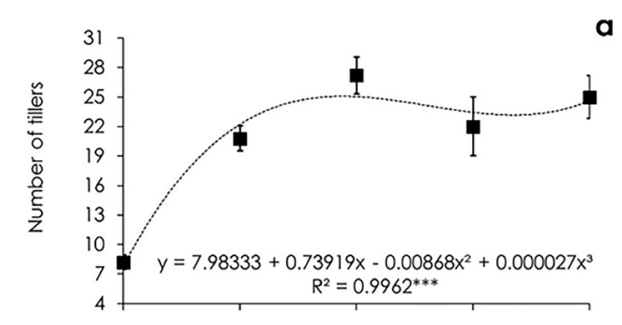

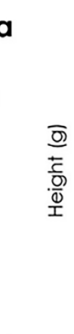
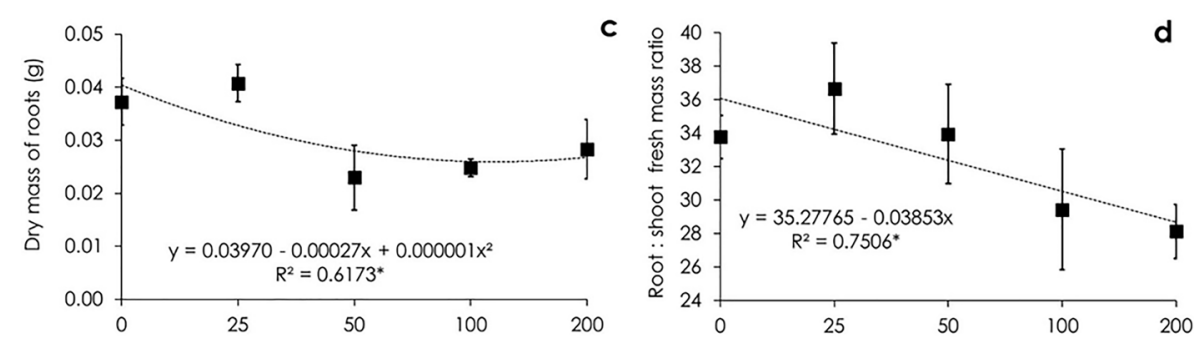

Figure 1. Effects of ethephon ( $\mathrm{mg} \mathrm{L}^{-1}$ ) on the number of tillers (a); main tiller height (b); roots dry mass (c) and root: shoot fresh mass ratio (d) of sugarcane seedlings 'IAC 95-5000'. Bars: standard errors. * and ***: significant regression equations at 0.05 and 0.0001 of error probability, respectively. 


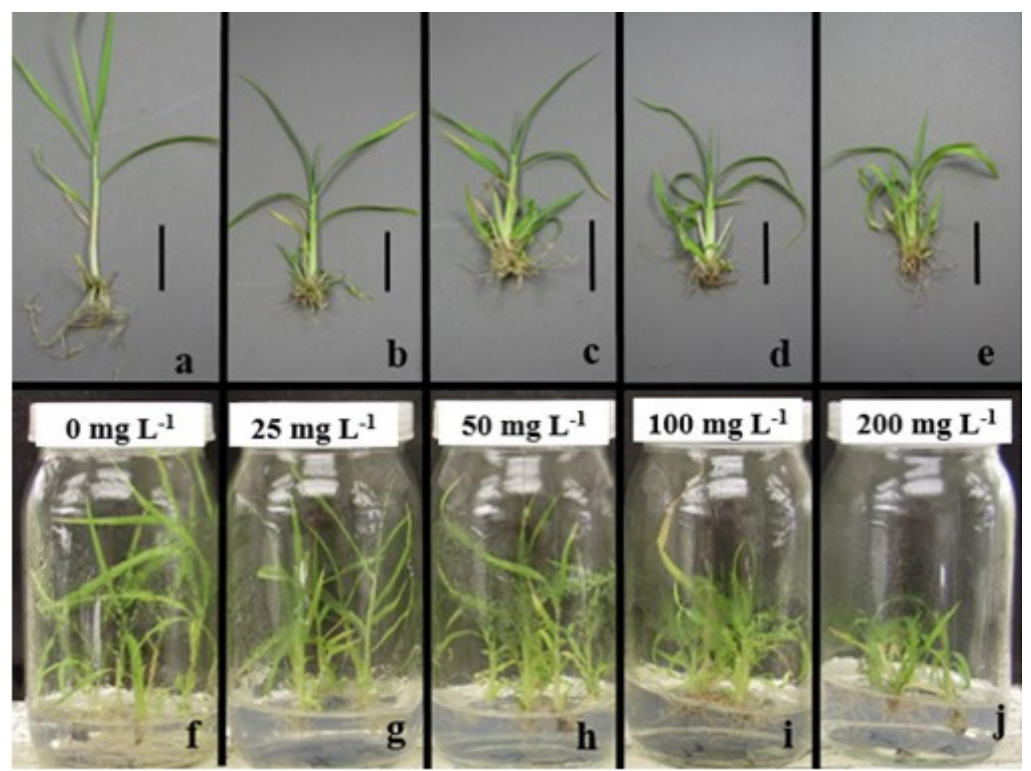

Figure 2. Morphophysiological changes caused by ethephon on 'IAC 95-5000' sugarcane seedlings, at 30 days after addition of this plant regulator to the culture medium. Scale bars: $2 \mathrm{~cm}$.
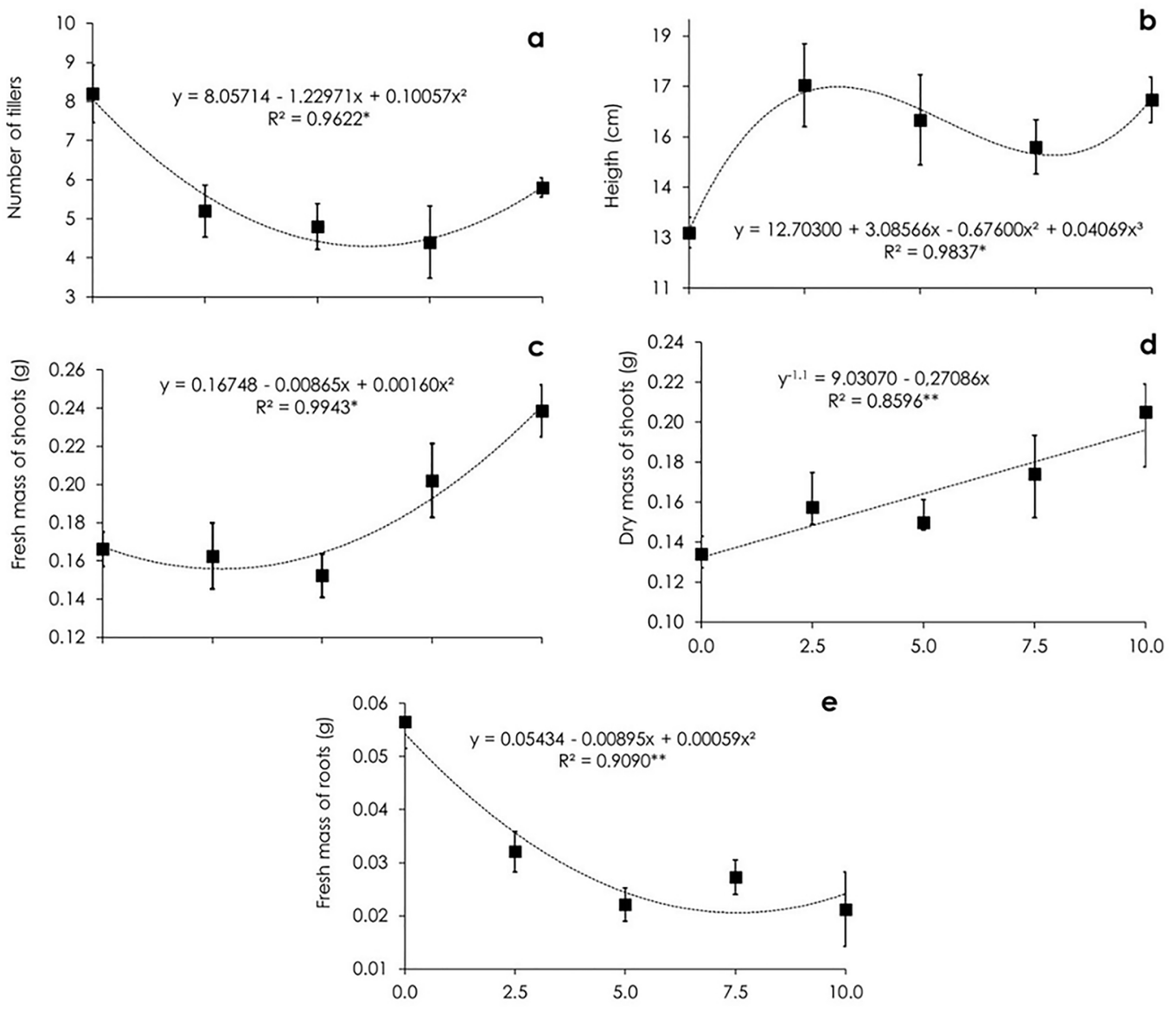

Figure 3. Gibberellic acid ( $\mathrm{mg} \mathrm{L}^{-1}$ ) effects on the number of tillers (a); main tiller height (b); shoot fresh (c) and dry (d) mass and roots fresh (e) mass of sugarcane seedlings 'IAC 95-5000'. Bar: standard error. * and **: significant regression equations at 0.05 and 0.001 of error probability, respectively. 
of parenchymatous cells, and reductions in the amount of sclerenchyma fibers in sugarcane (Martins \& Castro, 1999). Since these fibers are responsible for plant support, the high lodging tendency of explants treated with gibberellic acid may be related to the reductions in the amount of sclerenchyma fibers. Application of gibberellin also inhibited the sugarcane tillering (approximately 48\%, Figure 3 ) and changed the root: shoot ratios (Figure 5), probably by inhibition of the meristem initiation and/or by changing metabolism of several endogenous hormones (Gaspar et al., 1996).

It is concluded that addition of ethephon to the culture medium is a potential strategy to enhance in vitro production of 'IAC 955000' sugarcane, since it increases the number of usable shoots in subsequent subcultures. However, tested doses of gibberellin negatively affected the seedling development, because it impaired shoot and root growth.

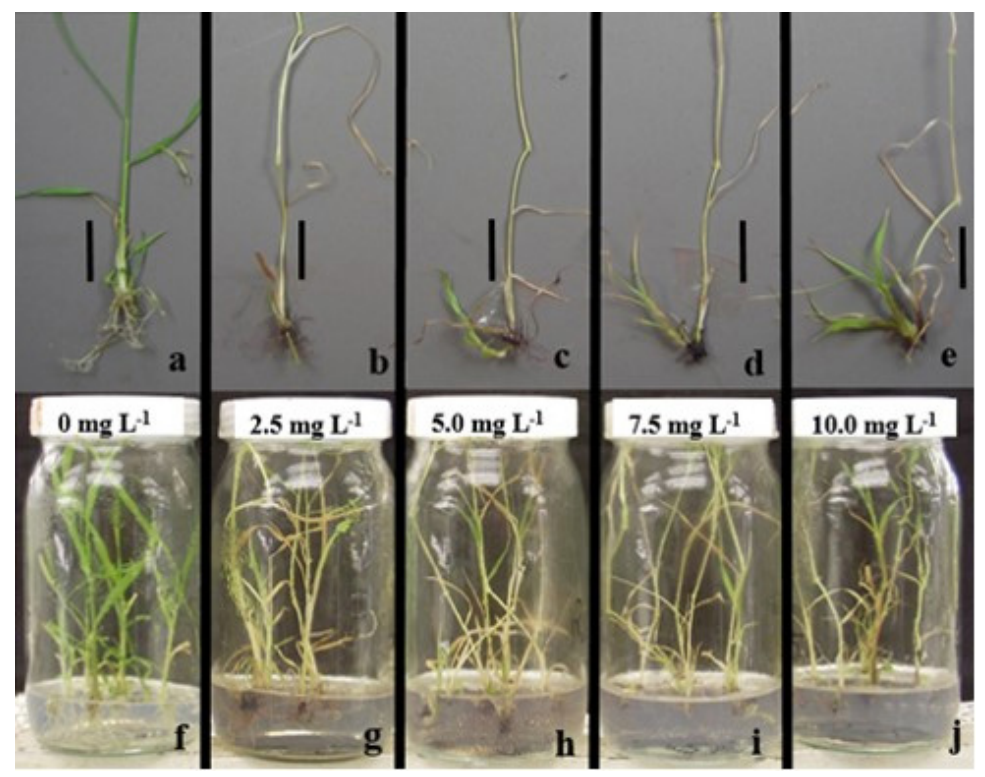

Figure 4.Morphophysiological changes caused by gibberelic acid on 'IAC 95-5000' sugarcane seedlings, at 30 days after addition of this plant growth regulator to the culture medium. Scale bars: $2 \mathrm{~cm}$.
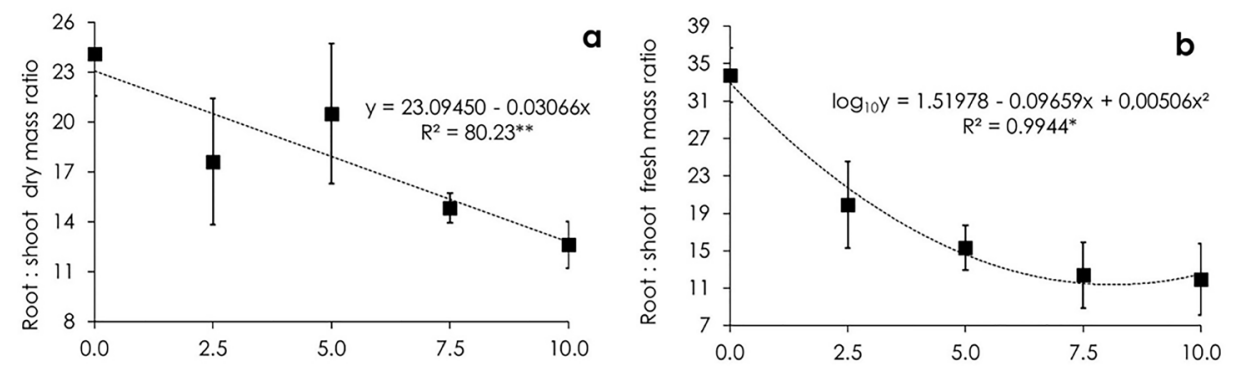

Figure 5. Gibberellic acid ( $\mathrm{mg} \mathrm{L}^{-1}$ ) effects on root: shoot ratio based on dry (a) or fresh (b) mass of sugarcane seedlings 'IAC 95-5000'. Bar: standard error. * and **: significant regression equations at 0.05 and 0.001 of error probability, respectively.

\section{References}

Begum, M.K., Islam, M.O., Miah, M.A.S., Hossain, M.A., Islam, N. 2011. Production of somaclone in vitro for drought stress tolerant plantlet selection in sugarcane (Saccharum officinarum L.). The Agriculturists 9: 18-28.

Costa, S.M., Mazzola, P.G., Silva, J.C.A.R., Pahl, R., Pessoa, A., Costa, S.A. 2013. Use of sugar cane straw as a source of cellulose for textile fiber production. Industrial Crops and Products 42: 189-194.

Davies, P.J. 1995. Plant hormones: physiology biochemistry and molecular biology. Kluwer Academic Publishers, London, England. 833 p.

Davies, P.J.ed. 2010. Plant hormones: biosynthesis, signal transduction, action! Dordrecht, the Netherland, Heidelberg, Germany, London, UK, New York, NY, USA: Springer. 
Hajari, E., Snyman, J.S., Watt, M.P. 2015. Nitrogen use efficiency of sugarcane (Saccharum spp.) varieties under in vitro conditions with varied $\mathrm{N}$ supply. Plant Cell, Tissue and Organ Culture 122: 21-29.

Gabriele, S., Rizza, A., Martone, J., Circelli, P., Costantino, P., Vittorioso, P. 2010. The Dof protein DAG1 mediates PIL5 activity on seed germination by negatively regulating GA biosynthetic gene AtGA3ox1. The Plant Journal 61: 312-323.

Garcia, R., Cidade, D., Castellar, A., Lips, A., Magioli, C., Callado, C., Mansur, E. 2007. In vitro morphogenesis patterns from shoot apices of sugar cane are determined by light and type of growth regulator. Plant Cell, Tissue and Organ Culture 90: 181-190.

Gaspar, T., Kevers, C., Penel, C., Greppin, H. Reid, D.M., Thorpe, T.A. 1996. Plant hormones and plant growth regulators in plant tissue culture. In Vitro Cellular and Developmental Biology Plant 32: 272-289.

Gou, J., Strauss, S.H., Tsai, C.J., Fang, K., Chen, Y., Jiang, X., Busov, V.B. 2010. Gibberellins regulate lateral root formation in populus through interactions with auxin and other hormones. Plant Cell 22: 623-639.

Ikezaki, M., Kojima, M., Sakakibara, H., Kojima, S., Ueno, Y., Machida, C., Machida, Y. 2010. Genetic networks regulated by ASYMMETRIC LEAVES 1 (AS1) and AS2 in leaf development in Arabidopsis: KNOXgenes control five morphological events. The Plant Journal 6: 70-82.

Jha, T.B., Mukherjee, S., Basak, A., Adhikari, J. 2013. In vitro morphogenesis in Selaginella microphylla (Kunth.) Spring. Plant Biotechnology Reports 7: 239-245.

Lo, S.F., Yang, S.Y., Chen, K.T., Hsing, Y.L., Zeevaart, J.A.D., Chen, L.J., Yu, S.M. 2008. A novel class of gibberellin 2-oxidases control semidwarfism, tillering, and root development in rice. Plant Cell 20: $2603-2618$.

Maluta, F.A., Bordignon, S.R., Rossi, M.L., Ambrosano, G.M.B., Rodrigues, P.H.V. 2013. Cultivo in vitro de cana-de-açúcar exposta a diferentes fontes de luz. Pesquisa Agropecuária Brasileira 48: 1303-1307.

Martins, M.B.G., Castro, P.R.C. 1999. Efeitos de giberelina e ethephon na anatomia de plantas de cana-de-açúcar. Pesquisa Agropecuária Brasileira 34: 1855-1863.

Mauriat, M., Sandberg, L.G., Moritz, T. 2011. Proper gibberellin localization in vascular tissue is required to control auxin-dependent leaf development and bud outgrowth in hybrid aspen. The Plant Journal 67: 805-816.
Mishra, S., Nailwal, T.K., Pant, R.C. 2014. In vitro study of role of ethylene during tillering in sugarcane. Sugar Tech 16: 255-263

Murashige, T., Skoog, F.A. 1962. A revised medium for rapid growth and bioassays with tobacco tissue cultures. Physiologia Plantarum 15: 473-497.

Nadeau, C.D., Ozga, J.A., Kurepin, L.V., Jin, A., Pharis, R.P., Reinecke, D.M. 2011. Tissuespecific regulation of gibberellin biosynthesis in developing pea seeds. Plant Physiology 156: 897912.

Nikolic, R., Mitic, N., Ninkovic, S., Vinterhalter, B., Zdravkovic-Korac, S., Neskovic, M. 2010. Gibberellic acid promotes in vitro regeneration and shoot multiplication in Lotus corniculatus L. Plant Growth Regulation 62:181-188.

Niu, S., Li, Z., Yuan, H., Fang, P., Chen, X., Li, W. 2013. Proper gibberellin localization in vascular tissue is required to regulate adventitious root development in tobacco. Journal of Experimental Botany 64: 3411-3424.

Pesquet, E.,Tuominen H. 2011 . Ethylene stimulates tracheary element differentiation in Zinnia elegans cell cultures. New Phytologist 190: 138149.

Prameswara, V.A., Johnstona, M., Perkinsa, M., Robertson, V., Ratnadewic, D. 2009. Ethylene influences development and flowering of Ptilotus spp. in vitro and ex vitro. Scientia Horticulturae 122: 227-232.

Ramiro, D.A., Melotto-Passarin, D.M., Barbosa, M. A., Santos, F., Gomez, S.G.P., Massola Junior, N.S., Lam, E., Carrer, H. 2016. Expression of Arabidopsis Bax Inhibitor-1 in transgenic sugarcane confers drought tolerance. Plant Biotechnology Journal 14: 1-12.

Ribalta, F.M., Croser, J.S., Erskine, W., Finnegan, P.M., Lulsdorf, M.M., Ochatt, S.J. 2014. Antigibberellin-induced reduction of internode length favors in vitro flowering and seed-set in different pea genotypes. Biologia Plantarum 58: 39-46.

SAS Institute. 2011. SAS/STAT User's Guide: Statistics, version 9.3. SAS Institute. SAS Institute, Cary, EUA.

Smiullah, F. 2013. Callogenesis and organogenesis studies in some accessions of Saccharum officinarum. Journal of Agricultural Science 5: 171-178.

Snyman, S.J., Meyer, G.M., Koch, A.C., Banasiak, M., Watt, M.P. 2011. Applications of in vitro culture systems for commercial sugarcane production and improvement. In Vitro Cellular and Developmental Biology Plant 47: 234-249. 
Taiz, L., Zeiger, E. 2013. Fisiologia vegetal. 5. ed. Artmed, Porto Alegre, $954 \mathrm{p}$.

Trujillo-Moya, C., Gisbert, C. 2012. The influence of ethylene and ethylene modulators on shoot organogenesis in tomato. Plant Cell, Tissue and Organ Culture 111: 41-48.

Tsuchisaka, A., Yu, G.X., Jin, H.L., Alonso, J.M., Ecker, J.R., Zhang, X.M., Gao, S., Theologis, A. 2009. A combinatorial interplay among the 1-aminocyclopropane-1-carboxylate isoforms regulates ethylene biosynthesis in Arabidopsis thaliana. Genetics 183: 979-1003.

Waclawovsky, A.J., Sato, P.M., Lembke, C.G., Moore, P.H., Souza, G.M. 2010. Sugarcane for bioenergy production: an assessment of yield and regulation of sucrose content. Plant Biotechnological Journal 8: 263-276.

Zhao, C., Hanada, A., Yamaguchi, S., Kamiya, Y., Beers, E.P. 2011. The Arabidopsis Mybgenes MYRland MYR2 are redundant negative regulators of flowering time under decreased light intensity. The Plant Journal 66: 502-515.

Yasmin, S., Mensuali-Sodi, A., Perata, P., Pucciariello, C. 2014. Ethylene influences in vitro regeneration frequency in the FRI3A rice harbouring the SUBIA gene. Plant Growth Regulation 72: 97-103. 